\title{
Electrocatalytic Behavior of PtCu Clusters Produced by Nanoparticle Beam Deposition
}

\author{
Published as part of The Journal of Physical Chemistry virtual special issue "Metal Clusters, Nanoparticles, and \\ the Physical Chemistry of Catalysis". \\ Maria Chiara Spadaro, Jo J. L. Humphrey, Rongsheng Cai, Lidia Martínez, Sarah J. Haigh, Yves Huttel, \\ Steve J. Spencer, Andrew J. Wain, and Richard Palmer*
}

Cite This: https://dx.doi.org/10.1021/acs.jpcc.0c06744

Read Online

ABSTRACT: State-of-the-art electrocatalysts for electrolyzer and fuel cell applications currently rely on platinum group metals, which are costly and subject to supply risks. In recent years, a vast collection of research has explored the possibility of reducing the Pt content in such catalysts by alloying with earth-abundant and cheap metals, enabling co-optimization of cost and activity. Here, using nanoparticle beam deposition, we explore the electrocatalytic performance of $\mathrm{PtCu}$ alloy clusters in the hydrogen evolution reaction (HER). Elemental compositions of the produced bimetallic clusters were shown by X-ray photoelectron spectroscopy (XPS) to range from 2 at. $\%$ to 38 at. \% Pt, while high-angle annular dark field scanning transmission electron microscopy (HAADF-STEM) combined with energy dispersive X-ray (EDX) spectroscopy indicated

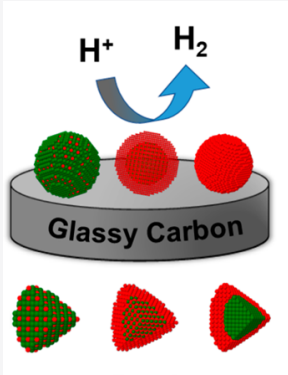

- Pt $\bullet \mathrm{Cu}$

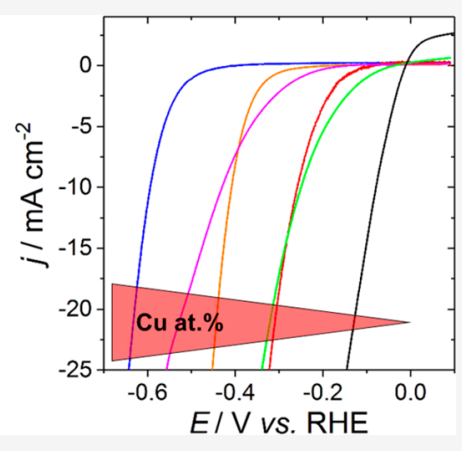
that the predominant cluster morphologies could be characterized as either a fully mixed alloy or as a mixed core with a Cu-rich shell. In contrast with previous studies, a monotonic decrease in HER activity with increasing Cu content was observed over the composition range studied, with the current density measured at $-0.3 \mathrm{~V}$ (vs reversible hydrogen electrode) scaling approximately linearly with $\mathrm{Pt}$ at. \%. This trend opens up the possibility that $\mathrm{PtCu}$ could be used as a reference system for comparing the composition-dependent activity of other bimetallic catalysts.

\section{INTRODUCTION}

Platinum represents the material of choice for many electrocatalytic reactions, including the oxygen reduction reaction (ORR), ${ }^{1}$ methanol oxidation reaction (MOR), ${ }^{2}$ and the hydrogen evolution reaction (HER), ${ }^{3}$ which lie at the core of energy conversion devices such as fuel cells and electrolyzers. However, the high cost and supply risks associated with Pt have been an obstacle to the widespread adoption of such green technologies and so substantial efforts have focused on developing catalysts with reduced Pt-content.

A general strategy in this context is to optimize catalyst nanoparticle size, the aim being to maximize surface area and Pt utilization, while ensuring that any surface site specific requirements for the catalytic reaction in question are met. ${ }^{4}$ Typical nanoparticle sizes for the above applications are of the order of a few nanometer, ${ }^{5}$ including size-selected clusters with controlled numbers of atoms, ${ }^{6-8}$ although recent work has highlighted the potential virtues of single atom catalysts (SACs). ${ }^{9-12}$

An alternative and widely explored approach to decrease reliance on $\mathrm{Pt}$ is to partially substitute some of the Pt-content with other cheap and earth-abundant materials (e.g., transition metals), ${ }^{13}$ while maintaining or even improving catalytic activity and stability. This may be achieved by producing core-shell nanoparticles in which the shell is rich in the active Pt catalyst while the secondary metal is concentrated at the core, replacing the redundant $\mathrm{Pt}^{14}$ The alloying of $\mathrm{Pt}$ with other transition metals may also induce beneficial strain effects, due to lattice disruptions resulting from the inclusion of metal atoms of different size. ${ }^{15}$ Also explored are ligand effects, in which manipulation of the $\mathrm{Pt}$ d-electron orbitals allows optimization of the binding strength between the reactants/ products at the surface. ${ }^{13,16}$

Among the many binary $\mathrm{Pt}$ systems, $\mathrm{PtCu}$ has received interest as an electrocatalyst for various reactions, including the ORR, MOR and HER. ${ }^{15,17-25}$ For the HER, which is the focus of the present study, alloying $\mathrm{Pt}$ with $\mathrm{Cu}$ has been

Received: July 23, 2020

Revised: October 3, 2020 
demonstrated to have beneficial effects. Tymoczko et al. studied $\mathrm{Pt}(111)$ electrodes modified with monolayer amounts of $\mathrm{Cu}$ and demonstrated a substantial enhancement in specific HER activity, attributed primarily to a ligand effect. ${ }^{18} \mathrm{Li}$ and co-workers synthesized alloyed $\mathrm{PtCu}$ nanospheres, approximately $50 \mathrm{~nm}$ in diameter, and demonstrated improved HER and ORR performance due to the addition of $\mathrm{Cu} .{ }^{19}$ In another example, a composite of randomly alloyed $\mathrm{PtCu}$ nanoparticles in the $2 \mathrm{~nm}$ range deposited onto a 3D architecture of carbon nanofibers was produced and shown to be an effective HER catalyst. $^{20}$ High activity has also been reported for $\mathrm{PtCu}$ atomically dispersed with $\mathrm{Pd}$ nanorings, creating a trimetallic ultrathin alloy. ${ }^{21}$ In addition to the direct use of $\mathrm{PtCu}$ as a catalyst, it has also been shown that selective dissolution of $\mathrm{Cu}$ located on the alloy surface can be used to generate a Pt-rich surface. $^{22}$

In the above examples, the catalysts were prepared by wet chemical methods. These can sometimes suffer drawbacks such as limited control over nanoparticle size, morphology, and composition, as well as possible chemical contamination or impurities resulting from the use of organic capping agents or surfactants to control nanoparticle growth, as well as generation of toxic by-products. An alternative approach to nanoparticle synthesis that has emerged in recent years is cluster (nanoparticle) beam deposition (CBD). ${ }^{10,26-35}$, In the most common approach, the cluster material is vaporized by magnetron sputtering in a vacuum chamber, before atoms are condensed in a noble gas to form a cluster beam, enabling deposition onto suitable substrates. CBD offers a number of potential advantages. $^{26}$ First, production of nanostructured materials can be achieved in a sustainable and environmentally friendly fashion, as it is a solvent and toxic byproducts free process. Second, the produced nanoparticles can be precisely controlled, in favorable cases, in terms of cluster size (by massfiltration), composition (by regulating the corresponding magnetron power), and structure. A severe limitation is the low amount of material produced, but a number of efforts have been recently devoted to scaling up the production rate in order to meet industrial research requirements. ${ }^{31,36,37}$ This method has proved to be successful for a number of application studies from generating advanced model catalysts for different chemical reactions to creating binding sites for protein molecules on biochips. ${ }^{27,28} \mathrm{PtCu}$ catalysts produced by CBD were the subject of a recent study by a number of the current authors focusing on gas phase acetylene semihydrogenation. ${ }^{29}$ In the present work, we use CBD to explore the effect of elemental composition on the electrocatalytic performance of $\mathrm{PtCu}$ clusters, specifically with respect to the hydrogen evolution reaction (HER).

\section{METHODS}

2.1. Cluster-Modified Electrode Preparation. Clustermodified electrodes were fabricated using a multiple ion cluster source (MICS) working in a UHV system (base pressure $5 \times$ $10^{-10}$ mbar), details of which are given elsewhere. ${ }^{30,31}$ Clusters were deposited onto $5 \mathrm{~mm}$ diameter glassy carbon (GC) disc electrodes which, prior to deposition, were polished to a mirror finish with microfiber polishing pads loaded with alumina suspension $(0.05 \mu \mathrm{m}$, Buehler UK) and rinsed with ultrapure water $(18.2 \mathrm{M} \Omega \mathrm{cm}$, Elga).

For the present work we used two of the three available magnetrons in the aggregation chamber, which contained the Pt (99.95\%, PIKEM) and Cu (99.95\%) targets for producing
$\mathrm{PtCu}$ alloy clusters as well as $\mathrm{Pt}$ and $\mathrm{Cu}$ reference clusters. The sputtering power, Ar gas flux, and condensation length (distance between the target and the exit nozzle) for each magnetron were controlled separately. ${ }^{32,33}$ The relative $\mathrm{Pt}$ content of the $\mathrm{PtCu}$ clusters produced lay in the range 2-38 at. \%. Cluster-modified GC electrodes with each $\mathrm{PtCu}$ composition were produced in duplicate for electrochemical tests, and clusters were also deposited onto transmission electron microscopy (TEM) grids and clean $\mathrm{Si} / \mathrm{SiO}_{x}$ substrates for high resolution imaging and X-ray photoelectron spectroscopy (XPS) analysis, respectively. The latter samples were also used for additional atomic force microscopy and scanning electron microscopy measurements (Figure S1) to evaluate the effect of the sputtering power on the obtained $\mathrm{Pt}$ and $\mathrm{Cu}$ content for each deposition (the sputtering power was adjusted accordingly to obtain the desired composition) and also obtain the cluster-support sticking coefficient in order to achieve a $30 \%$ cluster coverage (projected surface area) on the GC electrodes, thus avoiding significant cluster agglomeration.

2.2. Cluster Characterization. The average composition of each cluster sample was evaluated using XPS, while the cluster size, shape, structure, and composition were characterized at the single particle level by scanning transmission electron microscopy (STEM) and energy dispersive X-ray spectroscopy (EDX).

2.2.1. X-ray Photoelectron Spectroscopy. XPS was carried out in ultrahigh vacuum using a Kratos Axis Ultra instrument (Kratos Analytical Ltd., Manchester, U.K.). For each cluster sample, an area of approximately $700 \mu \mathrm{m} \times 300 \mu \mathrm{m}$ was analyzed. High-resolution spectra were acquired over appropriate binding energy ranges for $\mathrm{Pt} 4 \mathrm{f}$ and $\mathrm{Cu} 2 \mathrm{p}$ and were used to estimate the ratio of $\mathrm{Pt}$ to $\mathrm{Cu}$ in the clusters, assuming a homogeneous distribution across the samples. The monochromated aluminum X-ray source was operated at $15 \mathrm{kV}, 5$ $\mathrm{mA}$ emission. Analysis conditions used were $40 \mathrm{eV}$ pass energy, $0.1 \mathrm{eV}$ steps, and $0.5 \mathrm{~s}$ dwell per step. Five scans were acquired for the $\mathrm{Cu} 2 \mathrm{p}$ region and 10 scans for the $\mathrm{Pt} 4 \mathrm{f}$ region. The peak areas were calculated using Tougaard backgrounds, average matrix relative sensitivity factors, and the appropriate transmission function calibration. Errors in determining the $\mathrm{Pt} / \mathrm{Cu}$ ratio occur because the $\mathrm{Cu} 3 \mathrm{p}$ peak overlaps the $\mathrm{Pt} 4 \mathrm{f}$ region, such that higher concentrations of $\mathrm{Cu}$ cause larger errors in the measured $\mathrm{Pt}$ amount. It is estimated that, as a result of this, there is a $\sim 20 \%$ relative error in the $\mathrm{Pt} / \mathrm{Cu}$ ratio due to backgrounds and the measurement of peak areas.

2.2.2. Scanning Transmission Electron Microscopy and Related Spectroscopy. The cluster size, shape, structure, and composition were characterized by high angle annular dark field (HAADF) STEM and EDX using a spherical aberration probe corrected Thermo Fisher Titan microscope equipped with a ChemiSTEM Super-X Energy Dispersive X-ray detector operating at $200 \mathrm{kV}$. The incident electron beam convergence angle was $21 \mathrm{mrad}$ and $\mathrm{HAADF}$ images were collected with an inner angle of $55 \mathrm{mrad}$. All the images were acquired using Gatan's Digital Micrograph and analyzed using Fiji software. $3 \mathrm{D}$ atomic models in Figure 1 were realized using STEM_CELL ${ }^{35,38}$ and Rhodius software. ${ }^{4,39}$

2.3. Electrochemical HER Performance Testing. Electrochemical experiments were performed using a rotating disk electrode (RDE) apparatus (MSR Rotator, Pine Research Instrumentation) and an Ivium CompactStat potentiostat. A three-electrode configuration was used, comprised of the cluster-modified GC disc as a working electrode, a saturated 

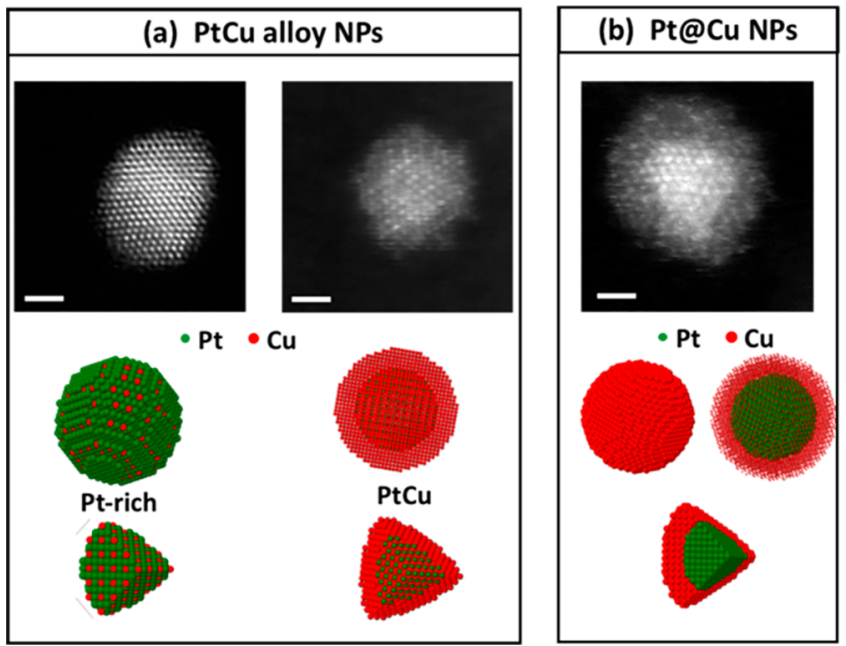

Figure 1. High resolution HAADF-STEM images of $\mathrm{PtCu}$ clusters (top) together with the corresponding idealized $3 \mathrm{D}$ atomic models qualitatively reflecting the atomic distribution observed (bottom: $\mathrm{Pt}$, green, and $\mathrm{Cu}, \mathrm{red}$ ). The models depict the entire particle together with a corresponding section to demonstrate composition variation from the center of the cluster to the surface. (a) Mixed alloy and (b) $\mathrm{Cu}$-rich shell morphology. Scale bars correspond to $1 \mathrm{~nm}$.

mercury/mercurous sulfate (MSE) reference electrode, and a GC rod as the counter electrode. Potentials were converted to the reversible hydrogen electrode (RHE) scale and all potentials quoted herein are against this reference potential unless otherwise stated. All measurements were performed at room temperature.

Electrochemical HER performance testing was undertaken in $0.5 \mathrm{M} \mathrm{H}_{2} \mathrm{SO}_{4}$ solution (Fisher, prepared using ultrapure water), which was deaerated by purging with hydrogen gas before and during measurements. Working in solutions of saturated hydrogen ensured that the thermodynamic potential for hydrogen evolution could be well-defined. Alternative electrolytes were considered due to the possible interference of sulfate anion adsorption on the HER process, but such effects were considered to have a minimal impact and so $\mathrm{H}_{2} \mathrm{SO}_{4}$ was selected to facilitate comparison with previous work on $\mathrm{PtCu}$ electrocatalysts. Samples were activated initially by cycling the potential between +0.2 and $-0.5 \mathrm{~V}$ at $100 \mathrm{mV} \mathrm{s}^{-1}$. In order to avoid dissolution of $\mathrm{Cu}$ prior to or during electrochemical measurements, the upper potential limit was not allowed to exceed $+0.2 \mathrm{~V}$. Above this potential, anodic currents clearly attributable to the electrochemical oxidation of $\mathrm{Cu}$ were observed. Linear sweep voltammograms (LSVs) were recorded from +0.2 to $-0.7 \mathrm{~V}$ at $5 \mathrm{mV} \mathrm{s}^{-1}$ and a rotation rate of 1600 rpm.

To account for variations in cluster surface area across the cluster-modified samples, recorded currents were normalized to the total deposited cluster surface area, as estimated from the known mass deposited and the average cluster size determined by TEM. All current densities $(j$, reported in $\mathrm{mA}$ $\mathrm{cm}^{-2}$ ) hence refer to current measured per unit of cluster surface area. The more conventional approach of determining the electrochemical surface area using hydrogen adsorption/ desorption or double layer capacitance were not considered reliable due to the large uncertainty associated with the low total metal loadings used.

\section{RESULTS AND DISCUSSION}

3.1. STEM Characterization of PtCu Clusters. To investigate the shape and atomic structure of $\mathrm{PtCu}$ clusters, HAADF-STEM imaging was performed and representative micrographs are shown in Figure 1 (top) along with the corresponding $3 \mathrm{D}$ atomic models. Here, the distinction between the two elements is simplified by the STEM image contrast at high collection angles, of which Rutherford scattering is the limit. ${ }^{40}$ The intensity depends on the atomic numbers $^{41}$ of the different elements, $Z$, to a power $N$, where $N$ lies between 1 and 2 . Therefore, $\mathrm{Pt}$ appears substantially brighter than $\mathrm{Cu}$. Two predominant cluster morphologies were observed: (i) well-alloyed clusters with differing amounts of $\mathrm{Pt}$ present and (ii) core-shell clusters in which the core is Pt-rich and the shell is $\mathrm{Cu}$-rich. 3D atomic models qualitatively depicting these two morphologies for the idealized case of a spherical NP are shown for illustration at the bottom of Figure 1. Figure 1a shows typical $\mathrm{PtCu}$ alloy structures, which we classified as either a Pt-rich alloy (as evaluated from atomic plane distancing analysis) or a $\mathrm{PtCu}$ alloy with $\mathrm{Cu}$-rich surface (here the $\mathrm{Cu}$ content is higher and therefore $\mathrm{Cu}$ atoms migrate more easily to the surface), shown on the left and right of Figure 1a, respectively. Figure $1 \mathrm{~b}$ shows a typical Pt-core@Cushell cluster. The average diameter of the produced clusters was measured to be in the range $4-6 \mathrm{~nm}$, as reported in Figure S2.
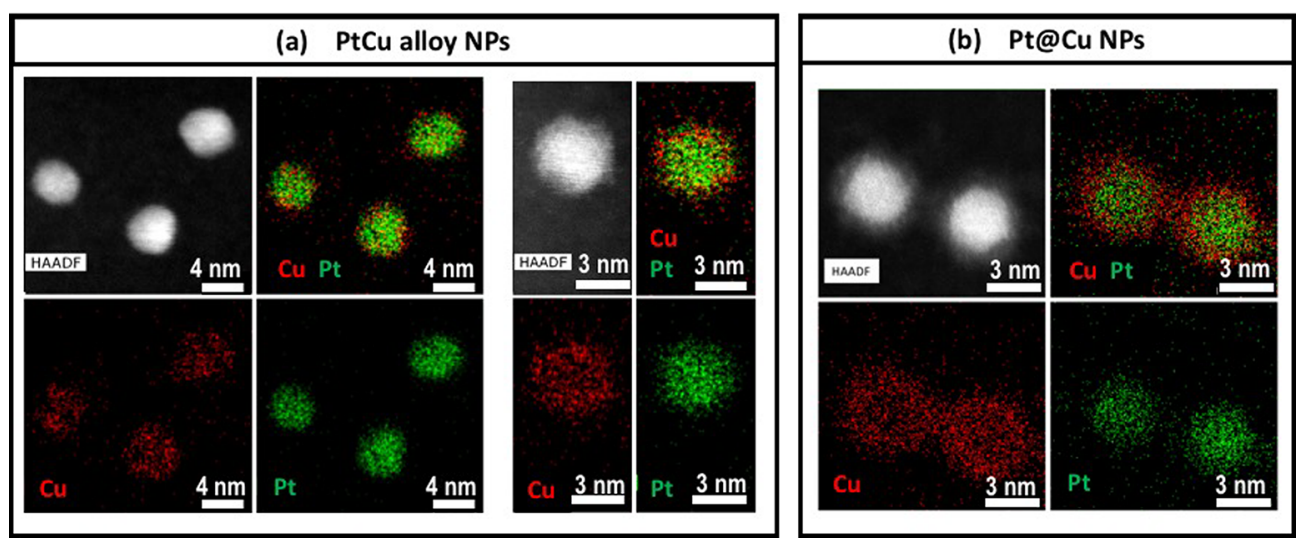

Figure 2. Elemental distribution analysis of PtCu alloy clusters recorded by STEM and EDX. Typical HAADF images together with single elemental distribution maps of $\mathrm{Cu}$ (red), $\mathrm{Pt}$ (green), and combined $\mathrm{Pt}-\mathrm{Cu}$ signals. (a) Mixed alloy and (b) Cu-rich shell morphology. 
The chemical composition of the produced $\mathrm{PtCu}$ clusters was explored at the individual particle level with STEM-EDX spectroscopy, as shown in Figure 2, where both $\mathrm{Pt}$ and $\mathrm{Cu}$ signals were detected in all samples. Depending on the cluster structure, the signals were either homogeneously distributed or localized in specific regions (core or shell). By integrating the resulting EDX spectra over the cluster area, it was possible to estimate the $\mathrm{Pt} / \mathrm{Cu}$ ratio for individual clusters. Figure 2a shows examples of clusters in which the $\mathrm{Pt}$ and $\mathrm{Cu}$ are homogeneously mixed across the cluster volume. On the left of this panel a group of three Pt-rich clusters is shown with a Pt/ $\mathrm{Cu}$ ratio of approximately $7: 1$, while on the right of the panel is a cluster with a $\mathrm{Pt} / \mathrm{Cu}$ ratio of approximately $1: 1$. Figure $2 \mathrm{~b}$ depicts $\mathrm{PtCu}$ clusters with a core-shell morphology, in this case with a $\mathrm{Pt} / \mathrm{Cu}$ ratio of approximately 2:1. The images confirm that core-shell clusters comprise a Pt-rich core surrounded by a $\mathrm{Cu}$-rich shell.

It is possible that the presence of a $\mathrm{Cu}$-rich shell is, at least in part, due to migration of $\mathrm{Cu}$ atoms from the core to the cluster surface after exposure of the sample to air; oxidation of the surface $\mathrm{Cu}$ atoms by atmospheric oxygen presents a driving force to concentrate $\mathrm{Cu}$ at the surface, ${ }^{42}$ in addition to the lower surface energy of $\mathrm{Cu}$, as observed in CuNi NPs. ${ }^{43}$ Close inspection of the right image of Figure 2a (alloy cluster) also shows some evidence of $\mathrm{Cu}$ enrichment at the surface, suggesting this migration effect may occur to varying degrees across all of the samples. The absence of a $\mathrm{Cu}$ shell in the left image of Figure $2 \mathrm{a}$ is then explicable by the low $\mathrm{Cu}$ content in these clusters. Table S1 shows the distribution of mixed alloy and core-shell cluster morphologies observed across the various samples produced.

3.2. XPS Characterization of PtCu Cluster Samples. XPS analysis was used to quantify the relative atomic percentages of $\mathrm{Pt}$ and $\mathrm{Cu}$ in the cluster samples. For these materials, the inelastic mean free path (IMFP) of the emitted photoelectrons is expected to be between 1 and $2 \mathrm{~nm}$, so we estimate the depth of information from the XPS analysis to be approximately $5 \mathrm{~nm}$. Since the average cluster radius was found to be in the range $2-3 \mathrm{~nm}$, the XPS analysis is expected to reflect the entire cluster composition, averaged across the deposited ensemble. Furthermore, any variations in the degree of surface-sensitivity of the XPS measurement resulting from the different IMFPs for $\mathrm{Pt}$ and $\mathrm{Cu}$ were also not considered to be substantial. Example high-resolution spectra are shown in Figure $3 \mathrm{a}$ and $3 \mathrm{~b}$ for the $\mathrm{Pt} 4 \mathrm{f}$ and $\mathrm{Cu} 2 \mathrm{p}$ regions, respectively. The spectrum in Figure 3a exhibits a large asymmetric feature from $\sim 82$ to $74 \mathrm{eV}$, which is comprised of contributions from Pt $4 \mathrm{f}_{5 / 2}$ and $\mathrm{Cu} 3 \mathrm{p}$ electrons, and a peak at $\sim 71 \mathrm{eV}$, corresponding to $\mathrm{Pt} 4 \mathrm{f}_{7 / 2}$. The $\mathrm{Pt}$ content, relative to the amount of $\mathrm{Cu}$, was determined on the basis of the $\mathrm{Pt} 4 \mathrm{f}_{7 / 2}$ peak, as indicated by the blue shaded region of Figure $3 \mathrm{a}$, but we note that there still remains some interference from the $\mathrm{Cu}$ $3 p$ feature, which extends underneath the $\mathrm{Pt} 4 \mathrm{f}_{7 / 2}$ peak, causing a slight underestimation of the Pt content despite background subtraction. The binding energy of the $\mathrm{Pt} 4 \mathrm{f}_{7 / 2}$ peak is indicative of $\mathrm{Pt}$ metal $^{44}$ but it is not possible to be certain if there is any oxidation because the peaks for oxidized Pt would be expected to overlap the $\mathrm{Cu} 3 \mathrm{p}$ peak. More detailed analysis was not possible due to the relatively low signal intensity of the $\mathrm{Cu} 2 \mathrm{p}$ and $\mathrm{Pt} 4 \mathrm{f}$ peaks, resulting from the relatively low amount of material present on the samples.

Figure $3 \mathrm{~b}$ shows the $\mathrm{Cu} 2 \mathrm{p}$ region from the same area of the same sample, in which the $\mathrm{Cu} 2 \mathrm{p}_{3 / 2}$ peak at $\sim 933 \mathrm{eV}$ is
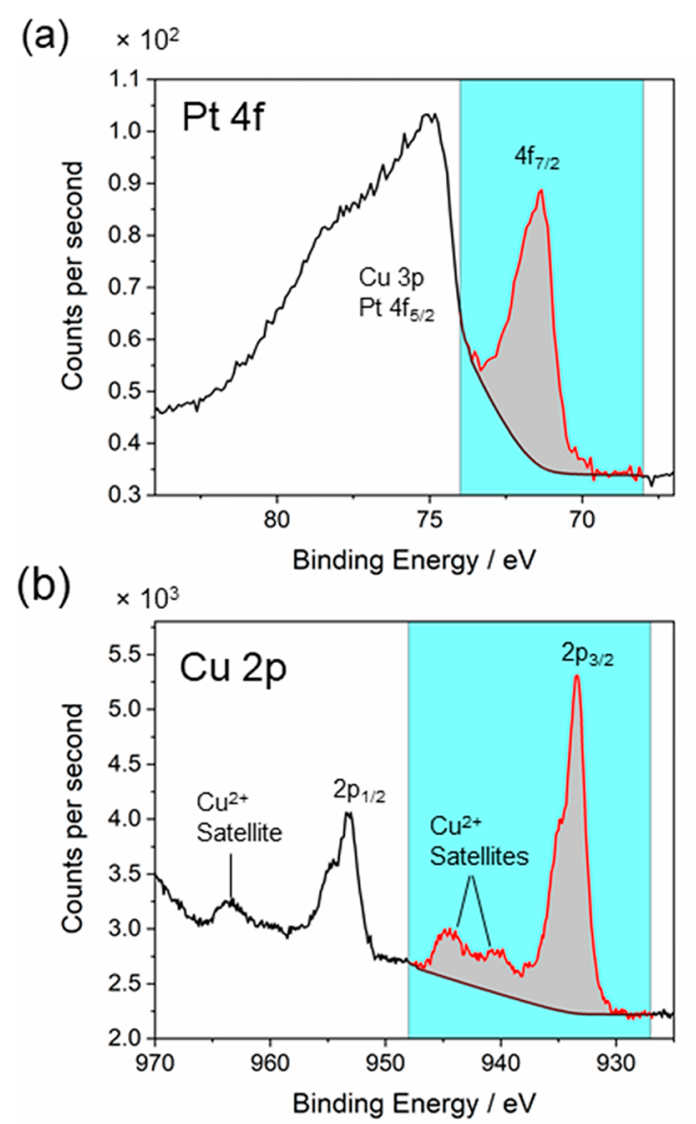

Figure 3. Example high resolution XPS spectra of a representative $\mathrm{PtCu}$ sample showing the quantification regions (highlighted in blue) and backgrounds used for peak quantification. (a) $\mathrm{Pt} 4 \mathrm{f}_{7 / 2}$ selected peak area and the $\mathrm{Pt} 4 \mathrm{f}_{5 / 2}$, plus $\mathrm{Cu} 3 \mathrm{p}$ peaks at higher binding energy, and (b) $\mathrm{Cu} 2 \mathrm{p}_{3 / 2}$ metal, oxide, and oxide satellite peaks selected for quantification and the $\mathrm{Cu} 2 \mathrm{p}_{1 / 2}$ peaks at higher binding energy.

indicative of either metallic $\mathrm{Cu}$ or $\mathrm{Cu}^{1+}$. This peak also appears to have a second component at slightly higher binding energy, suggesting the $\mathrm{Cu}$ is present in multiple oxidation states. This is confirmed by the observation of satellite peaks at a higher binding energy, ( 940, 945 , and $\sim 964 \mathrm{eV})$, which together are indicative of $\mathrm{Cu}^{2+}(\mathrm{CuO}){ }^{44}$ The area selected for $\mathrm{Cu}$ quantification (927-948 eV) contains the $\mathrm{Cu} 2 \mathrm{p}_{3 / 2}$ metal and oxide peaks, including the associated oxide satellite peaks. The presence of $\mathrm{Cu}$ in both metallic and oxidized forms is consistent with our conclusion above that surface oxidation may play a role in the observed cluster morphology: metallic $\mathrm{Cu}$ is likely localized in the core of the nanoparticle while oxidation takes place primarily on the surface.

The elemental compositions, in terms of relative $\mathrm{Pt}$ and $\mathrm{Cu}$ atomic \%, for the samples produced, are presented in Table S1, from which it can be seen that the Pt content in the binary clusters ranges between $2 \%$ and $38 \%$.

3.3. HER Performance of PtCu Clusters. The HER performance of the $\mathrm{PtCu}$ clusters, measured in $0.5 \mathrm{M} \mathrm{H}_{2} \mathrm{SO}_{4}$ solution, is captured in Figure 4. Representative linear sweep voltammetry (LSV) of different $\mathrm{PtCu}$ cluster decorated-GC electrodes are plotted. For the pure Pt sample, onset of HER occurs close to $0 \mathrm{~V}$ vs RHE, as expected, while more negative potentials are required to drive HER currents for the $\mathrm{PtCu}$ samples. The HER overpotential $(\eta)$ broadly shifts to more negative values with decreasing $\mathrm{Pt}$ content, although this is 
(a)

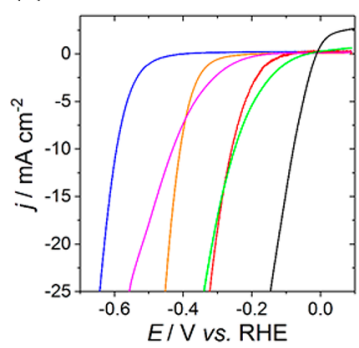

(c)

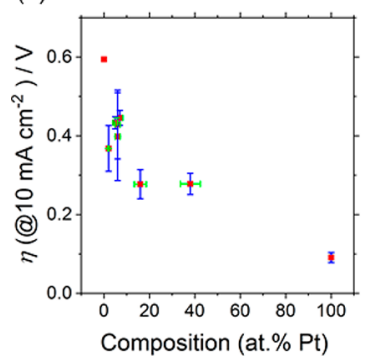

(b)

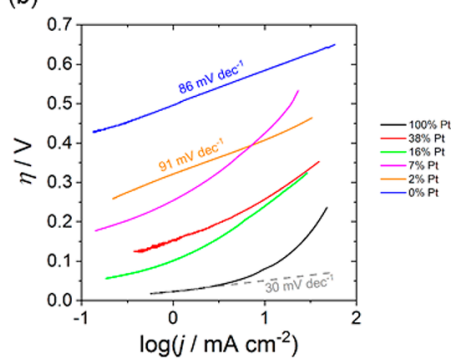

(d)

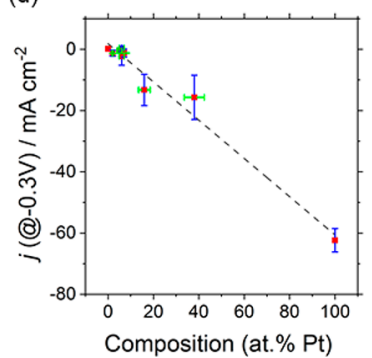

Figure 4. Electrochemical HER performance of PtCu clusters: (a) LSVs and (b) Tafel plots of a selection of PtCu samples with different compositions. (c) Overpotential required for a current density of 10 $\mathrm{mA} \mathrm{cm}{ }^{-2}$ and (d) current density measured at $-0.3 \mathrm{~V}$ plotted as a function of $\mathrm{Pt}$ atomic \%. Data plotted in parts $\mathrm{c}$ and $\mathrm{d}$ are mean values calculated from measurements on duplicate samples, and the vertical error bars (blue) reflect the calculated standard deviation. Horizontal error bars (green) are based on estimated error in XPS composition analysis (see Methods).

clearly complicated by differing onset curvatures. As expected, the pure $\mathrm{Cu}$ clusters exhibit the worst HER performance, with an overpotential comparable with that observed for polycrystalline $\mathrm{Cu} .^{45,46}$ Tafel plots for the data shown in Figure $4 \mathrm{a}$ are presented in Figure $4 \mathrm{~b}$. Linearity is only observed for the lowest Pt content samples shown, namely $0 \%$ and $2 \% \mathrm{Pt}$, which exhibit Tafel slopes of 86 and $91 \mathrm{mV} \mathrm{dec}^{-1}$, respectively. These values suggest that the mechanism of HER is close to being electron transfer limited. For the remaining samples the Tafel plots exhibit poor linearity so extraction of Tafel slopes was not attempted (a straight line with slope of $30 \mathrm{mV} \mathrm{dec}^{-1}$, which reflects the expected behavior for $\mathrm{Pt}$, is plotted tangential to the $100 \% \mathrm{Pt}$ data in Figure $4 \mathrm{~b}$ for reference only). The reason for the curved Tafel plots is unclear, but it possibly results from mass transport limitations influencing the current-potential behavior. Such limitations might be expected in the case of fast electron transfer, which would perhaps explain why the Tafel curvature is predominant for the more HER-active samples. While detailed analysis of this electrochemical data would therefore not be recommended, it is possible to explore general compositional trends.

To assess the impact of cluster composition on HER performance, the overpotential required to drive a current density of $10 \mathrm{~mA} \mathrm{~cm}$, averaged over measurements on duplicate samples, is plotted as a function of the relative atomic $\%$ of $\mathrm{Pt}$ in the $\mathrm{PtCu}$ clusters (as determined by XPS) in Figure 4c. Here, the general trend of increasing overpotential with decreasing Pt content can be seen most clearly. While the exact shape of this plot depends on the current density selected for comparison, in all cases the same broad trend is observed. To evaluate the HER current capability of electrocatalysts, it is common practice to report an exchange current density extrapolated to the equilibrium potential (in this case $0 \mathrm{~V}$ ).

However, given the curved nature of many of the Tafel plots, coupled with the wide range of HER overpotentials observed, this approach was considered inappropriate. Instead, the current densities are compared at a potential of $-0.3 \mathrm{~V}$, where the majority of samples exhibit measurable activity. The extracted current densities, plotted in Figure 4d, again reflect the decreasing HER activity with decreasing Pt content. Remarkably, a linear trend is observed between the current density measured at this potential and the Pt atomic \%, with the fitted line shown in Figure $4 \mathrm{~d}$ exhibiting an $R^{2}$ value of 0.960. Naturally, this linearity depends on the potential at which the current density is measured, and indeed at potentials of -0.2 and $-0.4 \mathrm{~V}$ the $R^{2}$ value of the linear correlation decreases to 0.900 and 0.699 , respectively. Nevertheless, the roughly monotonic decrease in HER activity with decreasing Pt content is an interesting observation, which indicates that addition of $\mathrm{Cu}$ does not impart any measurable electronic enhancement to the catalytic process. Instead, the $\mathrm{Cu}$ appears to simply decrease the HER performance of the Pt catalyst over the compositions studied, effectively diluting the $\mathrm{Pt}$ content. Due to the appreciable variations in the electrochemical properties observed across the various samples, we were unable to draw any solid conclusions regarding the precise relationship between cluster morphology and HER performance.

The observed negative impact of $\mathrm{Cu}$ on the HER performance of $\mathrm{Pt}$ is in contrast to a number of reports documenting an apparent improvement in catalytic activity of $\mathrm{Pt}$ alloyed with $\mathrm{Cu},{ }^{18-20}$ some of which are summarized in Table S2. However, the majority of the literature on simple binary $\mathrm{PtCu}$ alloys focus on samples with low $\mathrm{Cu}$ content (at most $\sim 25$ at. $\% \mathrm{Cu}$ ), which are substantially more Pt-rich than any of the binary $\mathrm{PtCu}$ clusters explored in this work (our $\mathrm{Cu}$ content lies in the range $62-98$ at. \%). It is therefore likely that the positive influence of $\mathrm{Cu}$ reported previously only applies for small quantities of $\mathrm{Cu}$ and is presumably offset by other unfavorable factors at higher $\mathrm{Cu}$ compositions, such that no such beneficial effects were observed in our work. Tymoczko et al. showed that addition of submonolayer amounts of $\mathrm{Cu}$ resulted a beneficial effect on the HER activity of $\mathrm{Pt}(111)$ but, more importantly, the spatial distribution of the $\mathrm{Cu}$ plays a defining role; enhanced HER activity was observed only in the case of near-surface $\mathrm{PtCu}$ alloying (i.e., Pt with subsurface $\mathrm{Cu}$ ), whereas top-surface alloying was found to have a detrimental effect, and the presence of a complete $\mathrm{Cu}$ overlayer was found to be highly deleterious toward HER activity. ${ }^{18}$ A significant fraction of the clusters studied in this work were shown to exhibit a $\mathrm{Cu}$-rich shell, resulting from the high $\mathrm{Cu}$-content, so it is likely that the negative impact of $\mathrm{Cu}$ surface alloys and overlayers dominate the HER behavior in our case. Such effects would be expected to become more pronounced with increasing $\mathrm{Cu}$ content, which we believe explains why, despite a multitude of contributing factors, the HER current density exhibits a broadly monotonic decrease with increasing $\mathrm{Cu}$ content.

\section{CONCLUSIONS}

In summary, using nanoparticle (cluster) beam deposition (CBD) synthesis of binary PtCu catalysts on GC supports, we have shown that alloying $\mathrm{Pt}$ with $\mathrm{Cu}$ at high $\mathrm{Cu}$ concentrations decreases the HER activity in a broadly monotonic fashion, which is in contrast to beneficial catalytic effects previously reported for small additions of $\mathrm{Cu}$. While the relatively poor 
HER performance of the $\mathrm{Cu}$-rich $\mathrm{PtCu}$ clusters investigated in this work precludes their application as water electrolyzer catalysts, the monotonic or even linear scaling of HER current with $\mathrm{Cu}$ content may offer some potential for $\mathrm{PtCu}$ to be used as reference system for comparing the composition-dependent activity of other bimetallic clusters. In other words, $\mathrm{Cu}$ appears to behave as an inert "dilutant" at high concentrations that acts to decrease the HER activity in a prospectively rather predictable way. This could be of particular benefit for researchers attempting combinatorial materials screening and would not be limited to CBD techniques.

\section{ASSOCIATED CONTENT}

\section{SI Supporting Information}

The Supporting Information is available free of charge at https://pubs.acs.org/doi/10.1021/acs.jpcc.0c06744.

AFM and SEM images, cluster morphology distribution, relative atomic \%Pt content evaluation and clusters size distribution (PDF)

\section{AUTHOR INFORMATION}

\section{Corresponding Author}

Richard Palmer - College of Engineering, Swansea University, Swansea SA1 8EN, U.K.; (1) orcid.org/0000-0001-87288083; Email: r.e.palmer@swansea.ac.uk

\section{Authors}

Maria Chiara Spadaro - College of Engineering, Swansea University, Swansea SA1 8EN, U.K.; (1) orcid.org/0000-00026540-0377

Jo J. L. Humphrey - National Physical Laboratory, Teddington TW11 OLW, U.K.

Rongsheng Cai - College of Engineering, Swansea University, Swansea SA1 8EN, U.K.; (1) orcid.org/0000-0002-2148-0563

Lidia Martínez - Instituto de Ciencia de Materiales de Madrid (ICMM-CSIC), Madrid 28049, Spain

Sarah J. Haigh - Department of Materials, The University of

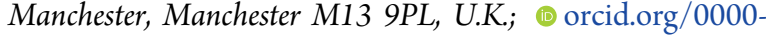
0001-5509-6706

Yves Huttel - Instituto de Ciencia de Materiales de Madrid (ICMM-CSIC), Madrid 28049, Spain

Steve J. Spencer - National Physical Laboratory, Teddington TW11 OLW, U.K.

Andrew J. Wain - National Physical Laboratory, Teddington

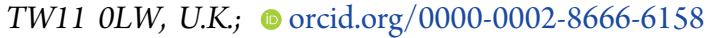

Complete contact information is available at:

https://pubs.acs.org/10.1021/acs.jpcc.0c06744

\section{Notes}

The authors declare no competing financial interest.

\section{ACKNOWLEDGMENTS}

We are most grateful to the European Union via EU H2020 Project CritCat (Project ID: 686053), led by J. Akola (Tampere/NTNU), for financial support. R.C. and S.J.H. would like to express thanks for the support from the EPSRC (Grant Reference No. EP/P009050/1). L.M. acknowledges financial support from the EC through ERC-2013-SYG610256 and "Comunidad de Madrid" and European Structural Funds (FotoArt-CM project S2018/NMT-4367). The MICS concept is the subject of the patent P201030059, PCT/ ES2011/070032 "Generation of Nanoparticles with Adjustable
Size and Controlled", now licensed by Oxford Applied Research Ltd.

\section{REFERENCES}

(1) Gomez-Marin, A.; Feliu, J.; Edson, T. Reaction Mechanism for Oxygen Reduction on Platinum: Existence of a Fast Initial Chemical Step and a Soluble Species Different from H2O2. ACS Catal. 2018, 8 (9), 7931-7943.

(2) Chung, D. Y.; Lee, K.-J.; Sung, Y.-E. Methanol Electro-Oxidation on the Pt Surface: Revisiting the Cyclic Voltammetry Interp retation. J. Phys. Chem. C 2016, 120 (17), 9028-9035.

(3) Zalitis, C. M.; Kucernak, A. R.; Sharman, J.; Wright, E. Design principles for platinum nanoparticles catalysing electrochemical hydrogen evolution and oxidation reactions: edges are much more active than facets. J. Mater. Chem. A 2017, 5 (44), 23328-23338.

(4) Piella, J.; Merkoci, F.; Genc, A.; Arbiol, J.; Bastus, N. G.; Puntes, V. Probing the surface reactivity of nanocrystals by the catalytic degradation of organic dyes: the effect of size, surface chemistry and composition. J. Mater. Chem. A 2017, 5 (23), 11917-11929.

(5) Garlyyev, B.; Kratzl, K.; Ruck, M.; Michalicka, J.; Fichtner, J.; Macak, J. M.; Kratky, T.; Gunther, S.; Cokoja, M.; Bandarenka, A. S.; Gagliardi, A.; et al. Optimising the size of platinum nanoparticles for enhanched mass activity in the electrochemical oxygen reduction reaction. Angew. Chem., Int. Ed. 2019, 58 (28), 9596-9600.

(6) von Weber, A.; Anderson, S. L. Electrocatalysis by Mass Selected Ptn clusters. Acc. Chem. Res. 2016, 49, 2632-2639.

(7) Schweinberger, F. F.; Berr, M. J.; Doblinger, M.; Wolff, C.; Sanwald, K. E.; Crampton, A. S.; Ridge, C. J.; Jackel, F.; Feldmann, J.; Tschurl, M.; et al. Cluster Size Effects in the Photocatalytic Hydrogen Evolution Reaction. J. Am. Chem. Soc. 2013, 135 (36), 13262-13265.

(8) Halder, A.; Curtiss, L. A.; Fortunelli, A.; Vajda, S. Perspective: Size selected clusters for catalysis and electrochemistry. J. Chem. Phys. 2018, 148, 110901 .

(9) Thomas, J. M. Tens of thousands of atoms replaced by one. Nature 2015, 525, 325-326.

(10) Liu, L.; Corma, A. Metal catalysts for heterogeneous catalysis: from single atoms to nanoclusters and nanoparticles. Chem. Rev. 2018, 118, 4981-5079.

(11) Zhang, H.; Lu, X. F.; Wu, Z.-P.; Lou, X. W. D. Emerging Multifunctional Single-Atom Catalysts/Nanozymes. ACS Cent. Sci. 2020, 6 (8), 1288-1301.

(12) Zhang, J.; Zhao, Y.; Guo, X.; Chen, C.; Dong, C.-L.; Liu, R.-S.; Han, C.-P.; Li, Y.; Gogotsi, Y.; Wang, G. Single platinum atoms immobilized on an MXene as an efficient catalyst for hydrogen evolution reaction. Nature Catalysis 2018, 1, 985-992.

(13) Yu, W.; Porosoff, M. D.; Chen, J. Review of Pt-Based Bimetallic Catalysis: From Model Surfaces to Supported Catalysts. Chem. Rev. 2012, 112, 5780-5817.

(14) Hunt, S. T.; Romàn-Leshkov, Y. Principles and methods for the rational design of core-shell nanoparticle catalysts with ultralow noble metal loadings. Acc. Chem. Res. 2018, 51, 1054-1062.

(15) Zhao, Y.; Wu, Y.; Liu, J.; Wang, F. Dependent Relationship between Quantitative Lattice Contraction and Enhanced Oxygen Reduction Activity over $\mathrm{Pt}-\mathrm{Cu}$ Alloy Catalysts. ACS Appl. Mater. Interfaces 2017, 9, 35740-35748.

(16) Kitchin, J. R.; Norskov, J. K.; Barteau, M. A.; Chen, J. G. Role of strain and ligand effects in the modification of the electronic and chemical properties of bimetallic surfaces. Phys. Rev. Lett. 2004, 93, 156801 .

(17) Du, Y.; Ni, K.; Zhai, Q.; Yun, Y.; Sheng, H.; Zhu, Y.; Zhu, M.; et al. Facile air oxidative induced dealloying of hierarchical branced $\mathrm{PtCu}$ nanodendrites with enhanced activity for hydrogen evolution. Appl. Catal., A 2018, 557, 72-78.

(18) Tymoczko, J.; Calle-Vallejo, F.; Schuhmann, W.; Bandarenka, A. S. Making the hydrogen evolution reaction in polymer electrolyte membrane electrolysers even faster. Nat. Commun. 2016, 7, 10990.

(19) Li, W.; Hu, Z.-Y.; Zhang, Z.; Wei, P.; Zhang, J.; Pu, Z.; Zhu, J.; He, D.; Mu, S.; Van Tendeloo, G. Nano-single crystal coalesced PtCu 
nanospheres as robust bifunctional catalyst for hydrogen evolution and oxygen reduction reactions. J. Catal. 2019, 375, 164-170.

(20) Wang, J.; Chen, J. W.; Chen, J. D.; Zhu, H.; Zhang, M.; Du, M. L. Designed Synthesis of Size-Controlled Pt-Cu Alloy Nanoparticles Encapsulated in Carbon Nanofibers and Their High Efficient Electrocatalytic Activity Toward Hydrogen Evolution Reaction. Adv. Mater. Interfaces 2017, 4 (1-8), 1700005.

(21) Chao, T.; Luo, X.; Chen, W.; Jiang, B.; Ge, J.; Lin, Y.; Wu, G.; Wang, X.; Hu, Y.; Zhuang, Z.; et al. Atomically dispersed copperplatinum dual sites alloyed with palladium nanorings catalyse the hydrogen evolution reaction. Angew. Chem., Int. Ed. 2017, 56 (50), 16047-16051.

(22) Nie, Y.; Li, L.; Wei, Z. Recent advancement in Pt and Pt-free catalysts for oxygen reduction reaction. Chem. Soc. Rev. 2015, 44, 2168-2201.

(23) Stamenkovic, V. R.; Fowler, B.; Mun, B. S.; Wang, G.; Ross, P. N.; Lucas, C. A.; Markovic, N. M. Improved Oxygen Reduction Activbity on Pt3Ni(111) via increased surface site availability. Science 2007, 315 (5811), 493-497.

(24) Mandegarzad, S.; Raoof, J. B.; Hosseini, S. R.; Ojani, R. Cu-Pt bimetallic nanoparticles supported metal organic framework derived nanoporous carbon as a catalyst for hydrogen evolution reaction. Electrochim. Acta 2016, 190 (1), 729-736.

(25) Chaudhari, N. K.; Hong, Y.; Kim, B.; Choi, S.-I.; Lee, K. Pt-Cu based nanocrystals as promising catalysts for various electrocatalytic reactions. J. Mater. Chem. A 2019, 7, 17183-17203.

(26) Grammatikopoulos, P.; Steinhauer, J.; Vernieres, J.; Singh, V.; Sowwan, M. Nanoparticle design by gas-phase synthesis. Advances in Physics: $X$ 2016, 1 (1), 81-100.

(27) Palmer, R. E.; Cai, R.; Vernieres, J. Synthesis without solvents: the cluster (nanoparticle) route to catalysis and sensors. Acc. Chem. Res. 2018, 51 (9), 2296-2304.

(28) Roy, C.; Sebok, B.; Scott, S. B.; Fiordaliso, E. M.; Sørensen, J. E.; Bodin, A.; Trimarco, D. B.; Damsgaard, C. D.; Vesborg, P. C. K.; Hansen, O.; et al. Impact of nanoparticle size and lattice oxygen on water oxidation on NiFeOxHy. Nature Catalysis 2018, 1, 820-829.

(29) Ayodele, O. B.; Cai, R.; Wang, J.; Ziouani, Y.; Liang, Z.; Spadaro, M. C.; Kovnir, K.; Arbiol, J.; Akola, J.; Palmer, R. E.; et al. Synergistic Computational-Experimental Discovery of Highly Selective PtCu Nanocluster Catalysts for Acetylene Semihydrogenation. ACS Catal. 2020, 10 (1), 451-457.

(30) Llamosa, D.; Ruano, M.; Martinez, L.; Mayoral, A.; Roman, E.; Garcia-Hernandez, M.; Huttel, Y. The ultimate step towards a tailored engineering of core@shell and core@shell@shell nanoparticles. Nanoscale 2014, 6 (22), 13483-13486.

(31) Martinez, L.; Lauwaet, K.; Santoro, G.; Sobrado, J.; Peláez, R.; Herrero, V.; Tanarro, I.; Ellis, G.; Cernicharo, J.; Joblin, C.; et al. Precisely controlled fabrication, manipulation and in-situ analysis of $\mathrm{Cu}$ based nanoparticles. Sci. Rep. 2018, 8 (1), 7250.

(32) Martínez, L.; Mayoral, A.; Espiñeira, M.; Roman, E.; Palomares, F.; Huttel, Y. Core@shell, Au@TiOx nanoparticles by gas phase synthesis. Nanoscale 2017, 9, 6463-6470.

(33) Mayoral, A.; Llamosa, D.; Huttel, Y. A novel Co@Au structure formed in bimetallic core@shell nanoparticles. Chem. Commun. 2015, $51,8442-8445$.

(34) Pelli Cresi, J. S.; Spadaro, M. C.; D’Addato, S.; Valeri, S.; Benedetti, S.; Di Bona, A.; Catone, D.; Di Mario, L.; O'Keeffe, P.; Paladini, A.; et al. Highly efficient plasmon-mediated electron injection into cerium oxide from embedded silver nanoparticles. Nanoscale 2019, 11 (21), 10282-10291.

(35) Spadaro, M. C.; D’Addato, S.; Luches, P.; Valeri, S.; Grillo, V.; Rotunno, E.; Roldan, M. A.; Pennycook, S. J.; Ferretti, A. M.; Capetti, E.; et al. Tunability of exchange bias in $\mathrm{Ni@NiO} \mathrm{core-shell}$ nanoparticles obtained by sequential layer deposition. Nanotechnology 2015, 26 (40), 405704.

(36) Spadaro, M. C.; Zhao, J.; Terry, W. D.; Liu, J.; Yin, F.; Djurabekova, F.; Palmer, R. E. Angular dependence of nanoparticle generation in the matrix assembly cluster source. Nano Res. 2019, 12, 3069-3074.
(37) Palmer, R. E.; Cao, L.; Yin, F. Proof of principle of a new type of cluster beam source with potential for scale-up. Rev. Sci. Instrum. 2016, 87, 046103.

(38) Grillo, V.; Rotunno, E. STEM_CELL: a software tool for electron microscopy: part 1-simulations. Ultramicroscopy 2013, 125, 97-111.

(39) Arbiol, J.; Cirera, A.; Peiró, F.; Cornet, A.; Morante, J. R.; Delgado, J. J.; Calvino, J. J. Optimization of tin oxide nanosticks faceting for the improvement of palladium nanocluster epitaxy. Appl. Phys. Lett. 2002, 80 (2), 329-331.

(40) Oveisi, E.; Spadaro, M. C.; Rotunno, E.; Grillo, V.; Hebert, C. Insights into image contrast from dislocations in ADF-STEM. Ultramicroscopy 2019, 200, 139-148.

(41) Wang, Z. W.; Li, Z. Y.; Park, S. J.; Abdela, A.; Tang, D.; Palmer, R. E. Quantitative Z-contrast imaging in the scanning transmission electron microscope with size-selected clusters. Phys. Rev. B: Condens. Matter Mater. Phys. 2011, 84, 073408.

(42) Yin, F.; Wang, Z. W.; Palmer, R. E. Controlled formation of mass-selected $\mathrm{Cu}-\mathrm{Au}$ core-shell cluster beams. J. Am. Chem. Soc. 2011, 133 (27), 10325-7.

(43) Wolfbeisser, A.; Kovacs, G.; Kozlov, S. M.; Fottinger, K.; Bernardi, J.; Klotzer, B.; Neyman, K. M.; Rupprechter, G. Surface composition changes of $\mathrm{CuNi}-\mathrm{ZrO} 2$ during methane decomposition: An operando NAP-XPS and density functional study. Catal. Today 2017, 283 (1), 134-143.

(44) “Thermo Scientific website," [Online]. Available: http:// xpssimplified.com.

(45) Survila, A.; Kanapeckaite, S.; Pileckiene, J.; Budiene, J. Kinetics of hydrogen evolution on copper electrode involving organic acids as proton donors. Int. J. Electrochem. 2011, 2011, 1.

(46) Farinazzo Bergamo Dias Martins, P.; Papa Lopes, P.; Ticianelli, E. A.; Stamenkovic, V. R.; Markovic, N. M.; Strmcnik, D. Hydrogen evolution reaction on copper: promoting water dissociation by tuning the surface oxophilicity. Electrochem. Commun. 2019, 100, 30-33. 